\title{
Morte Súbita por Taquicardia Ventricular Polimórfica Catecolaminérgica em Criança
}

\author{
Sudden Death by Catecholaminergic Polymorphic Ventricular Tachycardia \\ in Children
}

Isabella João Milan ${ }^{1, *}$, Fernando Mello Porto², Halim Cury Filho², Adão Bento de Lucena Neto², Jose Marco Nogueira Lima²

ORCID IDs

Milan IJ (iD https://orcid.org/0000-0003-3497-3049

Porto FM (iD https://orcid.org/0000-0003-1503-4273

Cury Filho H (iD https://orcid.org/0000-0003-0102-4082

Lucena Neto AB (iD https://orcid.org/0000-0001-6946-1217

Lima JMN (D) https://orcid.org/0000-0002-9377-7649

\section{RESUMO}

A taquicardia ventricular polimórfica catecolaminérgica (TVPC) é uma doença cardíaca arritmogênica grave, hereditária, que acomete crianças e adultos jovens com coração estruturalmente normal. Sua prevalência é de um caso em 10 mil habitantes. É uma doença potencialmente fatal, que faz parte dos diagnósticos diferenciais de síncope em criança. O presente trabalho tem como objetivo relatar o caso de uma criança que, durante investigação de síncope convulsiva, apresentou morte súbita abortada devido à TVPC e abordar as dificuldades diagnósticas do caso, comparando com dados da literatura.

PALAVRAS-CHAVE: Taquicardia ventricular; Morte súbita cardíaca; Taquicardia.

\begin{abstract}
Catecholaminergic Polymorphic Ventricular Tachycardia (CPVT) is a severe cardiac arrhythmogenic hereditary illness, which affects children and young adults with a structurally healthy heart. Its prevalence is of one case in 10 thousand inhabitants. It is a potentially fatal illness, part of the differential diagnosis of syncope in children. The present study has the purpose of relating the case of a child that, during the investigation of convulsive syncope, presented sudden death aborted due to CPVT and to describe the diagnosis difficulties of the case, comparing with data from the literature.
\end{abstract}

KEYWORDS: Ventricular tachycardia; Cardiac sudden death; Tachycardia.

1. Hospital Municipal Dr. Mário Gatti - Clínica Médica - Campinas/SP - Brasil.

2.Grupo de Arritmia de Campinas - Campinas/SP - Brasil.

*Autor correspondente: isa_milan11@hotmail.com

Recebido: 18 Mar 2018 | Aceito: 5 Jul 2019

Editor Associado: José Mario Baggio Junior 


\section{INTRODUÇÃO}

A taquicardia ventricular polimórfica catecolaminérgica (TVPC) é uma doença cardíaca arritmogênica grave, hereditária, que acomete crianças e adultos jovens com o coração estruturalmente normal. Apresenta-se clinicamente como síncope, síncope convulsiva ou, em até 30\% dos casos, morte súbita, em situações de esforço físico ou emoções fortes ${ }^{1,2}$.

Deve-se aventar a suspeita clínica de TVPC quando há taquicardia ventricular polimórfica induzida adrenergicamente na ausência de qualquer outra anormalidade cardíaca estrutural ou elétrica ${ }^{3,4}$. Exames como o holter e, principalmente, o teste ergométrico podem consolidar a hipótese diagnóstica, pois, ao realizar o esforço físico ou passar por situações de estresse emocional, o eletrocardiograma pode evidenciar extrassístoles ventriculares polimórficas ou mesmo evocar a taquicardia ventricular ${ }^{5,6}$.

A confirmação diagnóstica se dá mediante estudo genético. $\mathrm{O}$ principal gene acometido é o autossômico dominante $R y R 2$, receptor da rianodina cardíaca, em aproximadamente $60 \%$ dos $\operatorname{casos}^{3,6-8}$. Porém, outros genes, como o autossômico recessivo CASQ2, que codifica a calsequestrina cardíaca, entre outros menos comuns, já foram confirmados como causadores da doença $a^{4}$.

A prevalência da TVPC é de um caso em 10 mil habitantes e, apesar de não tão rara, é uma doença subdiagnosticada por diversos fatores ${ }^{4}$. Uma das causas do subdiagnóstico é sua apresentação como síncope ou síncope convulsiva, o que leva, muitas vezes, a um primodiagnóstico errôneo de síncope vasovagal ou epilepsia ${ }^{8}$; outra causa do subdiagnóstico é devido ao coração estruturalmente normal que, somada ao desconhecimento da doença, faz com que patologias cardíacas sejam descartadas no início da investigação. Ainda, o estudo genético para confirmação diagnóstica muitas vezes não é acessível ${ }^{3}$.

O tratamento da TVPC é realizado com medidas comportamentais, como restringir atividades físicas intensas e evitar situações de emoções fortes, além de terapia medicamentosa com betabloqueadores como primeira opção de tratamento farmacológico, com controle de doença em cerca de dois terços dos $\operatorname{casos}^{2,4}$, e flecainida, antiarrítmico da classe I-C não comercializado no Brasil, para os não respondedores ou intolerantes ao betabloqueio'. Para pacientes refratários à terapia medicamentosa, há ainda a opção de denervação simpática cardíaca esquerda para diminuição das
TVPC e cardiodesfibriladores implantáveis para prevenção de morte súbita 5 .

Sendo assim, este trabalho tem como propósito contribuir para a literatura médica ao relatar um caso de morte súbita abortada por VPC em criança, com diagnóstico dificultado devido aos exames de maior acurácia diagnóstica estarem normais, objetivando o melhor entendimento sobre o tema.

\section{RELATO DE CASO}

Paciente GNA, sexo masculino, caucasiano, trazido pela mãe para primeira consulta há quatro anos, aos nove anos de idade, queixando-se de síncope convulsiva em situações de emoções fortes, exercícios físicos ou dor. Já havia passado por neuropediatra que, após investigação, encaminhou para a cardiologia. Negava demais queixas ou comorbidades e não havia dados positivos na história familiar.

Para investigação inicial do quadro, realizaram-se eletrocardiograma, ecocardiograma, holter de 24 horas, tilttable-test e teste ergométrico máximo. Todos os exames se apresentaram conforme a normalidade, porém o paciente continuava sintomático. Submetido, então, à colocação de um looper implantável que evidenciou um episódio de pausa sinusal durante a síncope, em situação de estresse por dor traumática.

O diagnóstico inicial com o achado foi de síncope vasovagal, apesar de o tilt-table-test ter sido normal. Optou-se por manter o looper implantável frente à clínica exuberante do paciente, que apresentou quadro de parada cardiorrespiratória (PCR) enquanto fazia atividade física. Foi reanimado, com reversão da morte súbita, e o looper implantável identificou ritmo de taquicardia ventricular polimórfica.

Realizados, então, estudo eletrofisiológico invasivo com isoprenalina endovenosa e estimulação ventricular progressiva, porém não induzida nenhuma taquiarritmia. Após esse episódio de PCR, como prevenção secundária de morte súbita, foi implantado um cardiodesfibrilador implantável (CDI) unicameral ventricular.

Realizado estudo genético que identificou mutação no gene RyR2, confirmando o diagnóstico de VPC, sendo iniciado tratamento clínico com betabloqueador, propranolol na dose de $40 \mathrm{mg}$ duas vezes ao dia, não tolerando doses maiores por hipotensão sintomática.

Devido ao quadro de ansiedade intensa do paciente, fazia muitos episódios de TVPC seguidos de choques 
apropriados do CDI, mesmo em uso de betabloqueador. Revisando a literatura, constatou-se que alguns casos de TVPC são refratários ao uso de betabloqueador, tendo indicação de associar ou introduzir flecainida para controle da doença. Entretanto, o antiarrítmico não é comercializado no Brasil e, após liberação judicial, o paciente passou a fazer uso contínuo de flecainida $50 \mathrm{mg}$ duas vezes ao dia e foi suspenso o propranolol, havendo controle clínico das terapias apropriadas do CDI, permanecendo atualmente há 24 meses sem episódios de TVPC.

\section{DISCUSSÃO}

A VPC é uma doença arritmogênica hereditária potencialmente letal, com mortalidade de 30 a $50 \%$ até os 30 anos de idade nos doentes não tratados, salientando a necessidade de diagnóstico precoce $e^{1,3,5,10}$. Devido à idade adiantada de sua apresentação, normalmente entre sete e 12 anos de idade, e ao fato de os pacientes terem coração sem alterações estruturais, muitos recebem diagnóstico errôneo de desregulação ortostática ou epilepsia, retardando, assim, o tratamento da TVPC ${ }^{5,11,12}$.

Após suspeita clínica de TVPC, são realizados exames não invasivos para solidificar a hipótese diagnóstica. $\mathrm{O}$ eletrocardiograma de repouso é normal, assim como o ecocardiograma. Na maioria dos casos, durante o teste de holter ou, principalmente, com o esforço no decorrer do teste ergométrico, pode-se evidenciar taquicardia ventricular polimórfica ou bidirecional, quando o paciente passa por situação de estresse físico ou emocional, ratificando a hipótese diagnóstica da TVPC. Quando o teste de esforço é

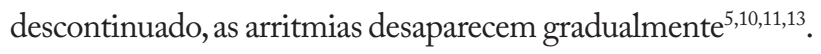

$\mathrm{Na}$ minoria dos casos em que os exames não invasivos não revelam alterações, pode-se realizar o estudo eletrofisiológico invasivo como complemento diagnóstico que evidencia taquicardia ventricular à estimulação com isoproterenol, medicação simpaticomimética que atua predominantemente como beta-agonista, em cerca de 30 a 75\% dos casos ${ }^{11}$.

A confirmação diagnóstica é feita por meio de estudo genético. Mutações no gene que codifica o receptor cardíaco de rianodina, $R y R 2$, são as alterações mais frequentes na TVPC, presentes em aproximadamente $60 \%$ dos casos. Essas mutações aumentam a liberação diastólica espontânea de cálcio do retículo sarcoplasmático, principalmente na presença de catecolaminas, predispondo, assim, às taquicardias ventriculares. Em situações fisiológicas, o cálcio deveria ser removido do meio intracelular na diástole por meio da troca de sódio por cálcio à custa de bomba de adenosina trifosfato (bomba de ATP) $)^{2-4,6-8,13}$.

Além das alterações no gene autossômico dominante $R y R 2$, a TVPC também pode ter mutações genéticas mais raras, como no gene $C A S Q 2$, que codifica a calsequestrina cardíaca e é de herança autossômica recessiva. É a segunda variante genética da doença, responsável por menos de 5\% dos casos. O gene CASQ2 é responsável pela recaptação de cálcio para o retículo sarcoplasmático durante a diástole. Mutações no gene diminuem a recaptação do cálcio, particularmente sob estresse adrenérgico, o que predetermina a TVPC. Raros casos de TVPC podem ainda ser esporádicos ${ }^{1,4,6,9}$.

$\mathrm{O}$ tratamento inicial da TVPC consiste em medidas comportamentais, como restringir atividades físicas intensas e situações que podem gerar grande estresse emocional, e terapia farmacológica com uso de betabloqueadores na dose máxima tolerada, pois, ao bloquear os receptores beta, há inibição da estimulação simpática, com boa resposta ao tratamento em cerca de dois terços dos casos ${ }^{1,3-6,9,12}$.

Para um terço dos pacientes refratários ou intolerantes aos betabloqueadores e que continuam apresentando eventos cardíacos arrítmicos, pode-se associar ou substituir o betabloqueador por flecainida, agente antiarrítmico da classe IC que, além de bloquear os canais cardíacos de sódio, inibe diretamente o gene $R y R 2$, diminuindo ainda mais a porcentagem de pacientes que mantém sintomas e eventos arrítmicos ${ }^{1-6}$.

Para pacientes refratários ao tratamento farmacológico máximo, há ainda outras opções terapêuticas, como o implante de CDI, indicado para todos como prevenção secundária de morte súbita e também para aqueles com TVPC muito sintomática, apesar da farmacoterapia. Há ainda a opção de denervação simpática cardíaca esquerda para os pacientes que habitualmente apresentam síncope ou TV polimórfica ${ }^{1,4,9,11}$.

O paciente deste estudo apresentava quadro clínico clássico, com início das síncopes convulsivas aos nove anos de idade, em situações de esforço físico ou estresse emocional. Porém, o diagnóstico foi dificultado, já que todos os exames não invasivos se apresentaram no padrão da normalidade, tendo o diagnóstico de TVPC firmado apenas após um episódio de morte súbita abortada, situação em que o looper implantável demonstrou a taquicardia ventricular 
polimórfica e o paciente foi então submetido à estudo genético que demonstrou a alteração típica da doença, a mutação no gene RyR2.

O tratamento do paciente também foi obstaculizado, já que, devido à sintomatologia intensa, o paciente sofreu bullying na escola, aumentando ainda mais o estresse emocional e, consequentemente, as síncopes convulsivas. Além disso, apresentou intolerância à terapia farmacológica de primeira linha, o betabloqueador, por apresentar hipotensão sintomática. Então, a próxima adversidade foi obter a flecainida, uma vez que a droga não é comercializada no Brasil, necessitando de ordem judicial para liberação.
No entanto, após uso da flecainida, o paciente obteve resposta completa ao tratamento, mantendo-se assintomático há 24 meses, sem necessidade de terapias adicionais. Faz uso do CDI como prevenção secundária à morte súbita, porém não faz terapias desde a introdução da flecainida.

\section{CONTRIBUIÇÃO DOS AUTORES}

Conceitualização, Milan I.J. e Porto F.M.; Metodologia, Milan I.J.; Investigação, Filho H.C, Neto A.B.L, Lima J.M.N.; Redação - Primeira versão, Milan I.J.; Redação - Revisão \& Edição, Milan I.J. e Porto F.M.; Supervisão, Porto F.M.

\section{REFERÊNCIAS}

1. Atik SU, Alp FE, Dedeoğlu R, Koka A, Öztunç F, Eroğlu AG. A rare cause of sudden cardiac arrest: catecholaminergic polymorphic ventricular tachycardia. Turk Pediatri Ars. 2018;53(2):124-8. https://doi.org/10.5152/ TurkPediatriArs.2017.3899.

2. Pérez FW, Afonso JSH, Marco MVG, Dorta EC, Acosta LA, Larrea OC, et al. Flecainide reduces ventricular arrhythmias in patients with genotype RyR2-positive catecholaminergic polymorphic ventricular tachycardia. Rev Esp Cardiol. 2018;71(3):185-91. https://doi.org/10.1016/j. rec.2017.04.032

3. Duan H, Lu Y, Qiao L, Hua Y, Li Y, Zhou K, et al. A delayed diagnosis of catecholaminergic polymorphic ventricular tachycardia with a mutant of RYR2 at c.7580T>G for 6 years in a 9-year-old child. Medicine. 2018;97(16):1-5. https://doi. org/10.1097/MD.0000000000010368

4. Velcea $A E$, Siliste C, Vinereanu D. Catecholaminergic polymorphic ventricular tachycardia - Looking to the future. Maedica (Buchar). 2017;12(4):306-10.

5. Napolitano C, Priori SG, Bloise R. Catecholaminergic polymorphic ventricular tachycardia. Gene Reviews. 2004; 633-39. https://doi.org/10.1016/B0-7216-0323-8/50071-3

6. Pölönen RP, Penttinen $K$, Swan $H$, Aalto-Setälä $K$. Antiarrhythmic effects of carvedilol and flecainide in cardiomyocytes derived from catecholaminergic polymorphic ventricular tachycardia patients. Stem Cells Int. 2018; https://doi.org/10.1155/2018/9109503

7. Lieve KWV, Verhagen JMA, Wei J, Bos JM, Werd C, Noguer FR, et al. Linking the heart and the brain: neurodevelopmental disorders in patients with catecholaminergic polymorphic ventricular tachycardia. Heart Rhythm. 2018;32(18):308269. https://doi.org/10.1016/j.hrthm.2018.08.025
8. Pan X, Phillippen L, Lahiri SK, Lee C, Park SH, Word TA, et al. In vivo Ryr2 editing corrects catecholaminergic polymorphic ventricular tachycardia. Circ Res. 2018;123(8):953-63. https://doi.org/10.1161/CIRCRESAHA.118.313369

9. Seidlmayer LK, Riediger F, Pagonas N, Nordbeck P, Ritter O, Sasko B. Description of a novel RyR2 mutation in a juvenile patient with symptomatic catecholaminergic polymorphic ventricular tachycardia in sleep and during exercise: a case report. J Med Case Rep. 2018;12(1). https://doi.org/10.1186/ s13256-018-1825-6

10. Ylänen K, Poutanen T, Hiippala A, Swan H, Korppi M. Catecholaminergic polymorphic ventricular tachycardia. Eur J Pediatr. 2010;169(5):535-42. https://doi.org/10.1007/ s00431-010-1154-2

11. Velasco A. Taquicardia ventricular polimórfica catecolaminérgica Rev Colom Cardiol. 2009;16(2):71-5.

12. Fujita $\mathrm{S}$, Nishida $\mathrm{K}$, Nakagawa $R$, Futatani $\mathrm{T}$, Igarashi $\mathrm{N}$, Usuda K, et al. Catecholaminergic polymorphic ventricular tachycardia managed as orthostatic dysregulation and epilepsy in 11- and 15-year-old sisters. Pediatr Int. 2018;60(11):998-1001. https://doi.org/10.1111/ped.13688

13. Domingo, AM. Genética de la taquicardia ventricular polimorfa catecolaminérgica; conceptos básicos. Arch Cardiol Méx. 2008;79(2):13-7.

14. Leite LR, Pereira KRP, Alessi SRB, Paola AAV. Taquicardia ventricular polimórfica catecolaminérgica. um importante diagnóstico em crianças com síncope e coração estruturalmente normal. Arq Bras Cardiol. 2001;76(1):63-8.

15. Oliveira ARF, Santiago GSL, Júnior EFX, Moser LRDN, Mourato FA, Mattos SS. Taquicardia ventricular polimórfica catecolaminérgica com morte súbita abortada. Rev Bras Cardiol. 2014;27(5):382-4. 